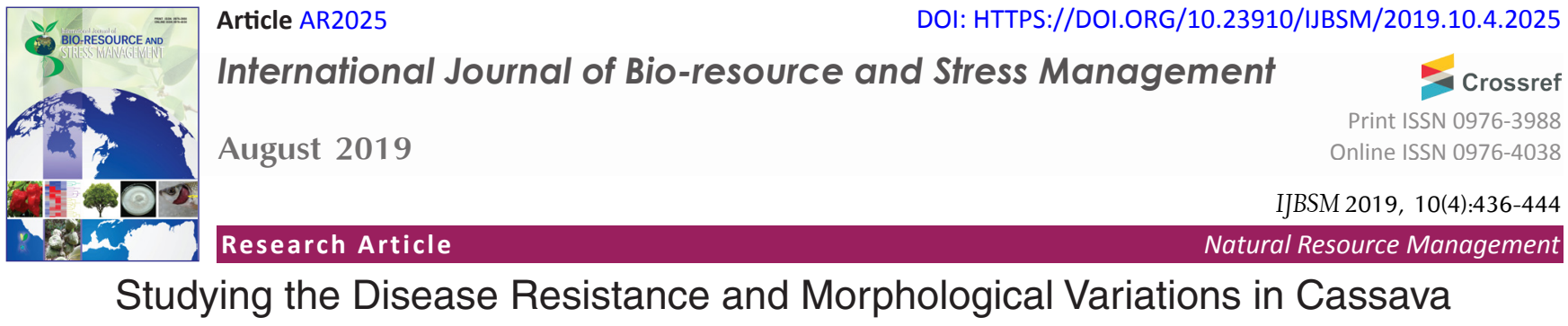

P. Vidya*, Aswathy G.H. Nair, C. Mohan, Ambu Vijayan and J. Sreekumar

ICAR-Central Tuber Crops Research Institute, Thiruvananthapuram, Kerala (695 017), India

\begin{tabular}{l}
\hline Open Access \\
Corresponding Author \\
P. Vidya \\
Citation: Vidya et al., 2019. Studying the Disease \\
Resistance and Morphological Variations in Cassava. \\
International Journal of Bio-resource and Stress \\
Management 2019, 10(4):436-444. HTTPS://DOI. \\
ORG/10.23910/IJBSM/2019.10.4.2019 \\
Copyright: (c 2019 Vidya et al. This is an open access \\
article that permits unrestricted use, distribution and \\
reproduction in any medium after the author(s) and \\
source are credited.
\end{tabular}

Data Availability Statement: Legal restrictions are imposed on the public sharing of raw data. However, authors have full right to transfer or share the data in raw form upon request subject to either meeting the conditions of the original consents and the original research study. Further, access of data needs to meet whether the user complies with the ethical and legal obligations as data controllers to allow for secondary use of the data outside of the original study.

Funding: The authors are grateful to the Director, Head, Division of Crop Improvement, ICAR-CTCRI, Thiruvananthapuram, for providing the laboratory facilities to do the work and University Grant Commission (UGC) for providing the financial support.

Conflict of interests: The authors have declared that no conflict of interest exists.

\begin{abstract}
Cassava is one of the most important tropical root crops with highest carbohydrate content feeding more than 800 million people all over the world. Cassava mosaic disease $(C M D)$ is a geminiviral disease which causes serious yield penalties in cassava production in tropical and sub-tropical regions. The most reliable and long lasting mechanism to combat CMD is to utilize host plant resistance especially through R-gene mediated resistance. The present study aimed to identify polymorphism between cassava cultivars viz., MNga-1 and $\mathrm{Cl}-732$ using resistant gene candidates (RGC) degenerate primers. This study utilized eight degenerate primers $(L 6, I, R P S 2, R P S 5, R P P 5, X a-1, N, R G C 2)$ to detect polymorphism and were observed between cassava cultivars amplified with primer pairs ( $I$, RPS2, RPS5, RPP5). A total of 60 single nucleotide polymorphisms (SNPs) were observed between two cassava cultivars which included 21 transitions and 39 transversions. The identified polymorphism was used to synthesize cleaved amplified polymorphic sequences (CAPS) marker computationally using CAPS designer tool of SOL GENOME NETWORK and identified three CAPS markers in susceptible cultivar amplified with RPP5. These cultivars were selected as male and female parent in CMD resistant breeding studies. True hybrid evaluations of the $F_{1}$ mapping populations were carried out using single allelic markers. Morphological characterizations of $F_{1}$ mapping population were carried out based on cassava descriptors mentioned by IITA, Nigeria and were grouped using cluster analysis. It was also found that more than half of the $F_{1}$ progenies (65) acquired morphological characters from female parent indicating the influence of female parent.
\end{abstract}

Keywords: Cassava, CAPS markers, SNP, transition, transversion

\section{Introduction}

Cassava, also known as manioc, tapioca, and yucca, is one of the most important tropical root crops with highest carbohydrate content feeding more than 800 million people (Burns et al., 2010). The cultivated cassava (Manihot esculenta Crantz) comes under Euphorbiaceae family, domesticated over 5,000-7,000 years BC along the southern and or northern rim of the Amazon basin (Duputie et al., 2009). The broad agroecological adaptability, its ability to mitigate unfavourable environmental condition and its abilities to produce reasonable yield makes cassava a food security turned cash crop. The average global cassava production was estimated to be $270.2 \mathrm{MT}$ in which $54.3 \%$ is accounted by Africa, $33.4 \%$ contributed by Asia and remaining $12.2 \%$ by Latin America (FAOSTAT, 2014). Indian production was accounted to be 4171000 ton

\title{
Article History
}

RECEIVED in $05^{\text {th }}$ August 2019 RECEIVED in revised form $28^{\text {th }}$ August 2019 ACCEPTED in final form $31^{\text {st }}$ August 2019 
from an area of 199000 ha (FAOSTAT, 2017). But the cassava production is always limited by Cassava mosaic disease (CMD), one of the most economically important Gemini viral disease causes a serious yield loss of 20 to $80 \%$. A severe loss of more than 19 million tons of cassava valued above US \$1.9 billion was reported in Africa in 2003 due CMD (Legg and Fauquet, 2004).

Plants have developed multiple mechanisms to defend various pathogens, of which viruses poses a serious threat to global agriculture as it cause a massive yield penalties in the concerned crop. To resist viral pathogen, plants relied on innate immune system contained multi-layered network of defense proteins. As an initial step of defense mechanism, plants developed pattern-triggered immunity (PTI) by which the immune system of the plant recognized a broad range of pathogens with conserved molecular patterns which were followed by effector-triggered immunity (ETI) acts inside the cell via various proteins encoded by a class of defense genes that can successfully intercept the invasion of pathogens were called R-genes (Hammond-Kosack and Jones, 1997; Dangl and Jones, 2001; Jones and Dangl, 2006; Lozano et al., 2015). The immediate response in R-gene mediated resistance mechanism was the hypersensitivity reaction in the infected region that restricted the spread of pathogen. This local hypersensitive response immunizes the plant against future infection by the same or closely related pathogen via systemic acquired resistance (SAR) occurs in tissues that were different from the initial infection site (Jennifer et al., 2005). R-genes were grouped into several classes based on the basis of different functional domains include the nucleotide binding leucine-rich repeats proteins (NLR), receptor-like proteins $(R L P)$, receptor-like kinases ( $R L K)$, including $L R R$-kinases and lectin receptor kinases, and intracellular protein kinases (PK) (Bent, 1996; Altschul et al., 1997; Hammond-Kosack and Jones, 1997). The most essential step in marker assisted breeding is the development of molecular markers to R-genes in the genome which is facilitated by the presence of conserved domain in the R-genes. Degenerate primers synthesized from the conserved consensus amino acid motifs of these functional domains were used to amplify Resistance gene analogues (RGAs) in several plant species (Azhar et al., 2011; Tarr and Alexander, 2009; Chen et al., 2007) and that had either provided structural CGs or useful marker for MAS.
With this in mind, present study made an attempt to identify polymorphism between cassava cultivars using RGC primers and identified polymorphism were used to develop CAPS markers.

In agricultural crops, true hybrid evaluation is a routine exercise carried out using DNA markers especially codominant markers were often used for the evaluation ( $\mathrm{Wu}$ et al., 2006; Selvakumar et al., 2010; Mbanjo et al., 2012; Semagn et al., 2012; Otti et al., 2011). The most desirable codominant markers were RFLP and SSR (Gomez et al., 2008) that were capable of showing homozygous polymorphic alleles in parents. Among the co-dominant markers, SSR markers were widely used because the heterozygosity of the hybrids could be easily determined by the presence of alleles from both the parents i.e., markers with one allele size per parent or markers with two allele sizes for one parent and a single allele size for the other parent. The characterization of plant materials using morphological traits has being used to assess the genetic diversity of cassava (Sambatti et al., 2001; Raghu et al., 2007; Benesi et al., 2010; Asare et al., 2011), to determine the divergence among genotypes (Rimoldi et al., 2010), and to verify the correlation among agronomic traits. Thus the present study focused to identify CMD resistant SNP variations in cassava and also study the true hybrids and morphological variations in $F_{1}$ mapping populations.

\section{Materials and Methods}

2.1. Studying the disease resistance in cassava using $R G C$ degenerate primers

\subsubsection{Sample collection}

In this study, two cassava cultivars were selected based on CMD resistance viz., Cl-732, CMD susceptible local cultivar and MNga-1 (TMS30001), CMD resistant cultivar developed by the International Institute for Tropical Agriculture (IITA), Nigeria. Samples collected and all the field trials were conducted in ICAR-Central Tuber Crop Research Institute (ICAR-CTCRI) from 2011-2015. The resistance in these cultivars was indexed as 5 -score and 1-score respectively based on symptom severity index (SSI) explained by Hahn et al. (1980; Table 1).

\subsubsection{DNA isolation and PCR amplification}

The genomic DNA was isolated from these cassava genotypes using Cetyl trimethyl ammonium bromide (CTAB) method

Table 1: CMD symptom severity score to determine the level of resistance

Symptom severity Score

Unaffected plant, no disease symptom

Mild chlorosis, mild distortions at the base of most leaves, while the remaining part of the leaves and leaflet appear green and healthy

Pronounced mosaic pattern on most leaves, narrowing and distortion of the one-third of the leaflets

Severe mosaic distortions of two thirds of most leaves and general reduction of leaf size and stunting of shoots 4

Very severe mosaic symptoms on all leaves, distortions, twisting, misshapen and severe leaf reductions of most leaves accompanied by severe stunting of plants. 
(Doyle and Doyle, 1990). Weighed $100 \mathrm{mg}$ of leaf samples and powdered properly using liquid nitrogen with sterile mortar and pestle. Added pre-warmed CTAB extraction buffer (1M Tris- $\mathrm{HCl}(\mathrm{pH} 8.0) ; 0.5 \mathrm{M}$ Ethylene diamine tetraacetic acid (EDTA) $\mathrm{pH} 8.0 ; 5 \mathrm{M} \mathrm{NaCl} ; 2$ g CTAB powder) containing $2 \%$ polyvinylpyrrolidine (PVP) and $0.2 \% \beta$-mercaptoethanol to the powdered leaf samples and grinded properly. The samples were incubated in water bath (Memmert) at $65^{\circ} \mathrm{C}$ for about $30 \mathrm{~min}$ and afterwards centrifuged the samples at 12,000 rpm for $10 \mathrm{~min}$ at room temperature. Transferred the supernatant to fresh tube and added equal volume of chlorform and isoamyl alcohol in 24:1 proportion into the supernatant. After thorough vortex, the samples were centrifuged at $12000 \mathrm{rpm}$ for $10 \mathrm{~min}$. The aqueous phase was transferred and added $5 \mu \mathrm{l}$ of RNase $\mathrm{A}\left(10 \mathrm{mg} \mathrm{ml}^{-1}\right)$ into the samples. After quick vortex, the samples were incubated at $37{ }^{\circ} \mathrm{C}$ for $1 \mathrm{hr}$. Again added equal volume of chloroform:isoamyl alcohol (24:1) to the samples and centrifuged the samples at $12,000 \mathrm{rpm}$ for 10 min. Transferred the aqueous phases in to new sterile tubes and added $500 \mu \mathrm{l}$ of ice-cold isopropanol, slightly inverted the tubes. The samples were then spun down at 12000 rpm for $5 \mathrm{~min}$. Discarded the supernatant and retained the pellets. Washed the pellets with $500 \mu \mathrm{l}$ of $70 \%$ ethanol and centrifuged at $5000 \mathrm{rpm}$ for $5 \mathrm{~min}$. The pellets were recovered after discarding the supernatant. The pellets were then dried and were finally suspended in $100 \mu$ of sterile double distilled water. The quality and purity of the DNAs were checked using $0.8 \%$ agarose gel and stained with ethidium bromide solution. The DNA bands were visualized using UV illumination system and gel images were taken using Gel documentation system (Alpha Imager). The quantification of DNA was determined on the basis of optical density readings (ODs) read at wavelengths of $260 \mathrm{~nm}$ and $280 \mathrm{~nm}$. The concentration of DNA samples

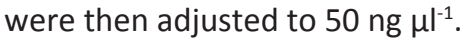

Polymorphism in these selected genotypes were carried out using RGC primers developed by Vasquez and Lopez (2012) (Table 2). A $20 \mu \mathrm{l}$ PCR reactions were performed containing $20 \mathrm{ng}$ DNA, $1 \mathrm{X}$ buffer $(10 \mathrm{mM}$ Tris- $\mathrm{HCl}(\mathrm{pH} 8.3), 50 \mathrm{mM} \mathrm{KCl}$, $1.5 \mathrm{mM} \mathrm{MgCl}_{2}$ ), $0.2 \mathrm{Mm}$ dNTPs, $0.5 \mu \mathrm{M}$ each of forward and reverse primers and $0.2 \mathrm{U}$ Taq polymerase (GeNei). Reaction cycle includes initial denaturation of $95^{\circ} \mathrm{C}$ for $3 \mathrm{~min} ; 45$ cycles of $94{ }^{\circ} \mathrm{C}$ for $45 \mathrm{~s}$, respective annealing temperature for each primer set at $45 \mathrm{~s}$ and $1 \mathrm{~min}$ of extension at $72{ }^{\circ} \mathrm{C}$; and final extension at $72{ }^{\circ} \mathrm{C}$ for $5 \mathrm{~min}$. The amplified products were resolved in $1.2 \%$ agarose gel stained with ethidium bromide. Then the PCR bands of corresponding size were eluted and purified using the QIA quick ${ }^{\circledR}$ gel extraction kit (Qiagen). These products were directly sequenced using $A B I 3500$ automated sequencer. The entire process includes DNA isolation, PCR amplification and elution and sequencing maintained two replications.

\subsubsection{Data analysis}

BLASTN was performed with the identified sequence and cassava genome in NCBI with default parameters. Functional annotations of the resulted sequences were and $\mathrm{NCBI}$ databases (Altschul et al., 1990) and Phytozome v12 (Goodstein et al., 2012). Expected value (E-value) gives an indication of the statistical significance of a given pair-wise alignment to infer sequence homology. Lower the E-value greater the sequence homology. The resultant sequences were submitted in NCBI and DDBJ.

\subsubsection{Detection of polymorphism and CAPS marker design}

The sequences of the both genotypes were checked by pairwise alignment using Clustal X version 2.0 (Larkin et al., 2007) and the variations were used to identify CAPS sites using CAPS designer tool in SOL GENOMICS NETWORK (Bombarely

Table 2: List of RGC primers used to study polymorphism in cassava

\begin{tabular}{|c|c|c|c|}
\hline Primer Name & Sequence in $5^{\prime}-3^{\prime}$ & Base pair size & Annealing temperature \\
\hline L6 & $\begin{array}{l}\text { R: TTTCAGAGGTGGAGATACCCGCAA } \\
\text { L: AAGCTCGTCTAGGCACCATCTTGA }\end{array}$ & 211 & $52{ }^{\circ} \mathrm{C}$ \\
\hline I & $\begin{array}{l}\text { R: CTTTGCACAAGGCATGAGCAGGAT } \\
\text { L: TGACCATGCCAAGGCGACATGTAT }\end{array}$ & 635 & $52{ }^{\circ} \mathrm{C}$ \\
\hline RPS2 & $\begin{array}{l}\text { R: AGACAGGCTTCCAACTCCAACTCA } \\
\text { L: TAAGCTCATTGGACATTGCCGTGC }\end{array}$ & 480 & $54^{\circ} \mathrm{C}$ \\
\hline RPS5 & $\begin{array}{l}\text { R: TGAAGCAGAGAAACACTGGTGGGA } \\
\text { L: AGGGTAGTGTAATGGGAGGAAATGGG }\end{array}$ & 304 & $58^{\circ} \mathrm{C}$ \\
\hline RPP5 & $\begin{array}{l}\text { R: AAGGCCTAGAAAGGCACTAAGCGA } \\
\text { L: TGTCGACACGGTTAAGGTATGGCA }\end{array}$ & 493 & $50{ }^{\circ} \mathrm{C}$ \\
\hline Xa-1 & $\begin{array}{l}\text { R: TGGGCCAAGATTTCTCACATCCCT } \\
\text { L: GCTCGTATATGCAGTGCTCCACTT }\end{array}$ & 666 & $54^{\circ} \mathrm{C}$ \\
\hline $\mathrm{N}$ & $\begin{array}{l}\text { R: GAGCTAAGCACTTCGGAGCTTTCA } \\
\text { L: TCTGACGAGCTTGTTCGATATTGT }\end{array}$ & 428 & $52{ }^{\circ} \mathrm{C}$ \\
\hline RGC2 & $\begin{array}{l}\text { R: TGATGTGTTGATGTGCTTCGTCCC } \\
\text { L: GGTATTTCTATGGACTAGCCGTGC }\end{array}$ & 253 & $50^{\circ} \mathrm{C}$ \\
\hline
\end{tabular}


et al., 2011).

2.2. Studying the morphological variations in $F_{1}$ mapping population

\subsubsection{Development of $F_{1}$ mapping populations}

The sexual hybridization was employed in the development of hybrid seeds. A total of 200 hybrid seeds were collected from hybridization between $\mathrm{Cl}-732$ and $\mathrm{MNga}-1$, which were dried in sunlight and stored. Before sowing, the seeds were soaked in water for 12 hours in night to ensure early germination. The non-viable seeds get floated on the surface and were eliminated. The submerged seeds were viable and were separated from water. A total of 158 viable seeds thus obtained were sowed in seed bed prepared in open field and were watered regularly. The sprouts started appearing on eight day onwards from the date of seed sowing. The rate of germination was evaluated for about one month and maximum germination was recorded on $16^{\text {th }}$ day ( $9 / 10$ seeds). A total of 130 seedlings were germinated and the remaining seeds did not germinate. The seedlings were maintained as such for one more month which developed single tap root. Later the seedlings were transplanted into individual mounts after removing the tap root.

\subsubsection{True hybrid evaluation of $F_{1}$ mapping population}

True hybrid evaluation of $F_{1}$ mapping population were carried out using 7 markers (SSRY83, SSRY339, NS890, SSRY95, SSRY33, SSRY47 and MeSSRY10) which showed single allelic size polymorphism among parental lines.

\subsubsection{Studying the morphological variations in $F_{1}$ mapping}

population

Morphological characterizations of $F_{1}$ mapping population were carried out based on cassava descriptors mentioned by IITA, Nigeria (Fukuda et al., 2010). Each character was studied within the $F_{1}$ progenies and was then compared with both parents to study the segregation pattern and categorized the entire population accordingly (Table 3).

\section{Results and Discussion}

An attempt was undertaken to study the polymorphism in cassava genotypes using RGC primer pairs. Plant disease resistance genes are those genes which have the ability to detect the pathogen attack and facilitate counter attack against pathogen. The two commonly occurring R-genes were NBS-LRR-Toll/interleukin-1-receptors (TIR or TNL) and NBS-LRR-coiled coil (CC) or CNL. Both R-genes contained several LRR at the C-terminus of their proteins which played a role in protein-protein interactions specifically while sensing the Avr molecules (Marone et al., 2013). Also TNL genes were found only in eudicot plants whereas CNL genes were found in both eudicots and monocots. The degenerate primers synthesized from R-genes helped to target the highly conserved domain of NBS domain. In this study, eight RGC primer pairs were used to detect the polymorphism in cassava genotypes includes $L 6, I$, RPS2, RPS5, RPP5, Xa-1, N, RGC2. Among these primers, $L 6, R P P 5$ and $N$ were grouped in TNL R-genes and I, RPS2, RPS5, Xa-1 and RGC2 were belonged to CNL R-genes. Out of eight primer pairs used, four primers produced considerable variations between the selected

\begin{tabular}{lllc}
\hline \multicolumn{2}{l}{ Table 3: Morphological traits used to evaluate $\mathrm{F}_{1}$ mapping populations } & Time (MAP) \\
\hline SL. No. & Morphological descriptor & Phenotypic classes & 3 \\
\hline 1. & Colour of apical meristem & Light green, Dark green, Purple green and purple & 6 \\
2. & Leaf retention & $\begin{array}{l}\text { Scale 1- very poor retention, Scale 2 - less than average, Scale 3-aver- } \\
\text { age, Scale 4 - better than average, Scale 5 - outstanding }\end{array}$ & 6 \\
3. & Shape of central leaflet & Lanceolate and Ellipitical-lanceolate & 6 \\
4. & Leaf colour & Light geen and dark green & 6 \\
5. & Number of leaf lobes & 3 lobes, 5 lobes and 7 lobes & 6 \\
6. & Petiole colour & Green, Greenish-red, Reddish-green and Pink & 6 \\
7. & Flowering & Non flowering, Green, Green-pink, Cream/white, Green-purple and Pink & 9 \\
8. & Colour of stem exterior & Silver, Orange, Light brown and greenish yellow & 9 \\
9. & Colour of stem cortex & Light green and dark green & At harvest \\
10. & Shape of the plant & Compact and open & At harvest \\
11. & Tuber skin colour & Dark brown, Light brown and Cream/white col-our & At harvest \\
12. & Tuber rind colour & Pink, White, Cream and Yellow & At harvest \\
13. & Tuber flesh colour & White, Cream and Yellow & At harvest \\
14. & Primary branching & & At harvest \\
15. & Secondary branching & Depends on the number of branches & At harvest \\
16. & Tertiary branching & &
\end{tabular}


cassava cultivars ( $I, R P P 5, R P S 2$ and RPS5) and the remaining four primer pairs did not show any sequence variations (L6, $X a-1, R G C 2$ and $N$ ) (Figure 1 and Figure 2). The primer / were reported to resist Fusarium oxysporum sp licopersicum, RPS2 and RPS5 resists Pseudomonas syringae bacteria and RPP5 against Hyaloperonospora arabidopsidis. A total of 60 SNPs were observed between two cassava cultivars viz., MNga-1 and $\mathrm{Cl}-732$. Among these SNPs, 21 were showing transitions and 39 were transversions. The transistion-transversion ratio in each primer pair were calculated and found to be 9:18 in RPP5, 5:10 in RPS5, 5:10 in I and 2:1 in RPS2. In addition to SNP variations, InDels were also found between the genotypes amplified with primer / and primer RPP5. A total of four InDels

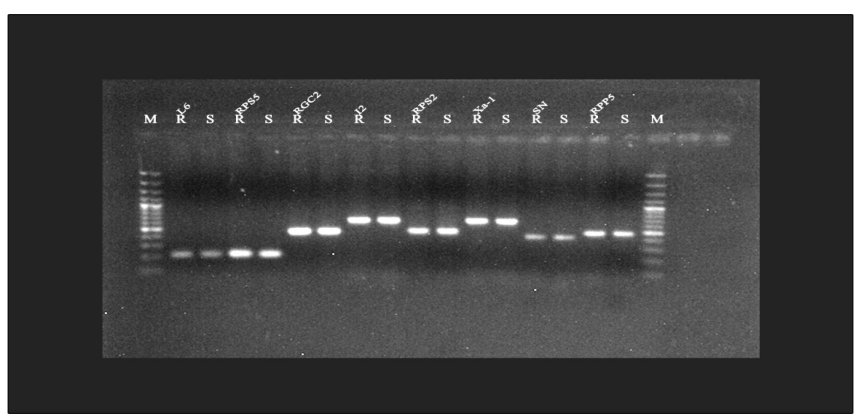

Figure 1: Amplifed products of RGC primer pairs in agarose gel were identified two with primer I and two with primer RPP5. Similar study was carried out by Vásquez and Lopez (2012) and observed a total of 37 SNPs were identified by comparing the sequence of $\mathrm{CM} 2177-2$ and TMS 30572 constituted 48.6 $\%$ transitions and $45.9 \%$ transversions.

The amplified fragments of each genotype with primer pairs viz., L6, I, RPS2, RPS5, RGC2 RPP5 and Xa-1 were analyzed using BLASTN using pair-wise alignment against cassava genome in $\mathrm{NCBI}$ and Phytozome v12 and the resultant sequences from both cutivars were submitted in NCBI (MF984391, MF984392, MF984393) and DDBJ (LC322308, LC322309, LC322310, LC322311). All the eight sequences were identified as disease resistance gene RFL-related. Each sequence was individually analyzed in $\mathrm{NCBI}$ and found that most of the sequences belong to either RPS2 or RPP13 disease resistant gene (Table 4).

The presence of SNP variations or InDel variation in resitriction edonuclease site could be used as CAPS markers. The present study also made an attempt to identify CAPS markers using CAPS designer tools in SOL GENOME NETWORK and identified three CAPS markers computationally in cassava genotypes amplified with those primers which showed polymorphism between cassava genotypes (Table 5). CAPS markers for disease resistance were based on the principle that CAPS site should present in resistant genotype and absent in susceptible genotype. In this study, it was found three CAPS sites were observed in susceptible genotype and no CAPS in resistant genotype amplified with RPP5 amplified sequences with remaining primers (RPS2, RPS5 and $I$ ) produced CAPS sites in both resistant and susceptible genotypes.

Cassava being an out crossing crop, the possibility of occurrence of contaminants in controlled hybridization was
PRIMER - I

TACAAATATTTTCACCGCTGTTACATGTACCGA-GATGATGAGTTGACTC

CAACTATACTA(A/T)GGAAC(A/T)C(C/T)TAGT(C/T)CTTAACTAG

AGATTT(G/C)ACCAGGAAGCTT(-/A)C(A/C)TTTG(T/A)GGAGGTA

CAGAACTGCAAATCTCC(A/-)GTATGTGACTAAGGAATC(C/T)TAACT

GTACGTGAAATTCTACTCTCTGCTCTTTACATGTCTACAGACTAAAATAT

TTGTATATTGGCCATTGAATTTA(A/T)GAGAAAGA(A/G)CAAAGAACC

(G/A)TTCTCTC(T/A)ATGTTTAAAATTTGAAGTACATGCCTTCCTGCA

(A/T)T(C/G)TTGTA(T/A)AATGCTTCCCCTTTGAGCTGCTTGAGTTG

\section{GAGTTGGAAGCCTGTTATTAAA}

\section{PRIMER - RPS2}

TAGATTAAGG-GTGCAGTAAACTTCTTATTTTTACCATTTTTG - CTTCTG

-GT ATA(C/G)ACACAAGTACATTCCAG(A/G)AA(G/A)CT---AGCA

AAAACATG-GAGTCACCTCTGTTACAGAAACCATTATGAAGAGTTGAATC CAACTTACAGTTA-AGATTCCTCAGTCACATACAGGTTAATGCAGTTCTG TACCTCCTCAAATGTGAGCTTCCTGG - TGAAATCTCTAGTTAATGACTAA GTGTTCCTTAGTATACTTGAAGTCATAACATCTGCTCTTTACATGTCTAT GCACTAAAATATTTGTAAATTGGCCATTGAATTTCAGAGAAAGAACAAAG AACCATTCTCTCTTATTTTTAGACTTGTATTACATGCATTCATGCGATGT TGTATAATTCTTCCCCTTTGAGCTGCTTGAGTTGGAGTTGGAAG-CCTGTC Primer - RPS5 GCTTTTCAGTTCTGTTTCCAAGATCTTGGGAGACGGTCTTGATTTTCATT TGTGCAGTAGTTTCTGTTCTACAAATTTTTGAATTTGTCCGTTGTGTTCC ATTTATTAAACCATAAAGCTTCTCATACTGTTTTGAAGGCAATTGTATTA GTAATAA(G/T)GAG(C/G)ATGAC(C/G)ATTGTATTACTATTTTGACA TTATGTT(A/G)TAC(A/T)G(A/G)A(A/G)TTATTA(A/T)CAAGAT (A/G)TTCCC(A/C)TTTC(C/T)TCCC(A/C)TTACACTACCCAGGGAC CCCTTA(T/G)GTC(T/G)GT(T/G)GTTCGATACTTAATGTTTCC TTTTTCATGGGTCAGGGCCCCTTTTCCTCCCATT

Primer-RPP5 CGGCCCTTTCCAGGG-TGAGGCACCTCTCTTTGAGGCGCTTGCCTTAGA$\mathrm{GA}$

AAA(-/A)GGCGCTAGGCGAGAGGTAGGCGAGGC(T/G)TCACTTGG(T/C) GCA(T/A)TTGCTTTT(-/A)TTTTATTATTAACTTTTTTAACTTTCA(A/C) GGG(T/A)TTTTAACTTAGAACCCCAAAGTTATAACGACAGCTAGGTATGT CTCTCACTCTCCCCTTTCTCTCTTTCTTTTTCTTCTATGCCCGCTCC(C/T) GTAGGCATTATACAATACTTTATTTTTTTTCTT(T/C)TCCCTTTTT(C/T) CCCCTC(T/C)TCCCCCC(T/C)CCC(T/C)CCCAACACCAAACA(A/C)CC TTTTTTTTATCT(T/A)CA(A/T)TTTTTTTTTA(T/A)TACTTTATGTA (T/C)CC(T/G)TGTTGTTTT(A/T)T(T/G)GC(T/A)AATTTT(T/A)G AAAAATTTTA(T/A)AAATTATA(G/T)AT(T/C)ACTTGC(T/A)AAT (T/A)TATTTTA(A/T)ATAGGTTCTGATACTTTGACTCTACTTTTTCCCA TACCACAACCGTGTCAACAA

Figure 2: Identification of SNP variations in cassava genotypes using RGC primer pairs

more. So the evaluation of the obtained seeds as true hybrid was an essential criterion for the establishment of true segregating population. The true hybrid analysis of $F_{1}$ mapping population was carried out using size specific polymorphic markers especially markers produced single alleles in parental lines. Seven single allelic size specific polymorphic markers (SSRY95, SSRY33, SSRY83, SSRY339, SSRY47, MeSSR10 and NS890) obtained from parental analysis were used in true 


\begin{tabular}{|c|c|c|c|c|c|c|c|}
\hline $\begin{array}{l}\text { Sl. } \\
\text { No. }\end{array}$ & $\begin{array}{c}\text { Primers } \\
\text { used }\end{array}$ & Transition & $\begin{array}{l}\text { Trans-ver- } \\
\text { sion }\end{array}$ & Length & Search Homology & E-value & Accession numbers \\
\hline 1. & I & 5 & 10 & 353 & $\begin{array}{l}\text { Manihot esculenta disease resis- } \\
\text { tance protein RPS2 }\end{array}$ & $8 e-88$ & MF984391, LC322308 \\
\hline 2. & RPS2 & 2 & 1 & 425 & $\begin{array}{l}\text { Manihot esculenta disease resis- } \\
\text { tance protein RPS2 }\end{array}$ & $3.1 \mathrm{e}-39$ & MF984392, LC322309 \\
\hline 3. & RPS5 & 5 & 10 & 319 & $\begin{array}{l}\text { Manihot esculenta probable dis- } \\
\text { ease resistance protein }\end{array}$ & $4 e-120$ & MF984393, LC322310 \\
\hline \multirow[t]{2}{*}{4.} & RPP5 & 9 & 18 & 465 & $\begin{array}{l}\text { NB-ARC domain (NB-ARC) // } \\
\text { Leucine Rich Re-peat (LRR_3) // } \\
\text { TIR domain }\end{array}$ & $1.8 \mathrm{e}-170$ & LC322311 \\
\hline & Total & 21 & 39 & & & & \\
\hline
\end{tabular}

\begin{tabular}{|c|c|c|c|c|}
\hline Enzyme & Recognition sequences & R current site & S current site & CAPS site \\
\hline BsaHI & $\mathrm{G}[\mathrm{A} \mid \mathrm{G}] \mathrm{CG}[\mathrm{C} \mid \mathrm{T}] \mathrm{C}$ & None (467) & $79(79,388)$ & $\begin{array}{l}\text { R: gtaggcgaGGCTTCacttgg } \\
\text { S: gtaggcgaGGCGTCacttgg }\end{array}$ \\
\hline Maelll & GT.AC & None (467) & $80(80,387)$ & $\begin{array}{l}\text { R: taggcgaggcTTCACttggt } \\
\text { S: taggcgaggcGTCACttggc }\end{array}$ \\
\hline Rsal & GTAC & None (467) & $343(343,124)$ & $\begin{array}{l}\text { R: tactttatGTATccttgttg } \\
\text { S: tactttatGTACccgtgttg }\end{array}$ \\
\hline
\end{tabular}

hybrid evaluation. For heterozygous population, possession of alleles from both parents was considered as true hybrid. It was found that out of 130 seedlings obtained, only 114 $F_{1}$ progenies were identified as true hybrid and were used in further CMD mapping study (Figure 3 and Figure 4). The utility of these markers in true hybrid evaluation was evident from previous studies done in cassava by Otti et al. (2011) and Mohan et al. (2013). True hybrid validation at the seedling

\begin{tabular}{|c|c|c|c|c|c|c|c|}
\hline SI. & \multicolumn{2}{|c|}{ Parents } & & \multicolumn{3}{|c|}{$F_{1}$ Progeny } & \multirow[t]{2}{*}{ SSR markers } \\
\hline 18 & $\mathrm{R}$ & $S$ & $\begin{array}{l}\mathrm{P}_{1} \\
\mathrm{ac}\end{array}$ & $\begin{array}{l}\mathrm{P}_{2} \\
\mathrm{ad}\end{array}$ & $\begin{array}{l}\mathrm{P}_{3} \\
\mathrm{bc}\end{array}$ & $\begin{array}{l}\mathrm{P}_{4} \\
b d\end{array}$ & \\
\hline & & $c-$ & & & $\mathrm{c}-$ & & $\begin{array}{l}\text { SSRY83, SSRY339, } \\
\text { NS890, SSRY95,, }\end{array}$ \\
\hline & $b-$ & & & & $b-$ & & $\begin{array}{l}\text { SSRY33， SSRY47, } \\
\text { MeSSRY10 }\end{array}$ \\
\hline
\end{tabular}

Figure 3: Segregation pattern of single allelic markers in $F_{1}$ mapping population stage is one of the essential criteria for inter-specific hybrid production and also for clonal propagation. Such hybrids were essential to map genes controlling various economically important traits. Molecular markers based hybrid purity tests have been used in many crop species such as rice (Yashitola et al., 2002; Sundaram et al., 2008; Tamilkumar et al., 2009, Bora et al., 2016), maize (Asif et al., 2006; Salgado et al., 2006), cotton (Selvakumar et al., 2010) and safflower (Naresh et al., 2009), Eucalyptus (Subashini et al., 2014).

The characterization of plant materials using morphological traits has being used to assess the genetic diversity of cassava (Sambatti et al., 2001; Raghu et al., 2007; Benesi et al., 2010; Asare et al., 2011), to determine the divergence among genotypes (Rimoldi et al., 2010), and to verify the correlation among agronomic traits. Based on the morphological characters, the entire $F_{1}$ genotypes and parents (MNga- 1 and $\mathrm{Cl}$-732) were grouped into two main clusters. First cluster contained male parent, MNga-1 and $49 \mathrm{~F}_{1}$ genotypes, of which KM-33, KM-1, KM-62, KM-84 and KM-133 were closer to MNga-1. Second cluster contained female parent, $\mathrm{Cl}-732$

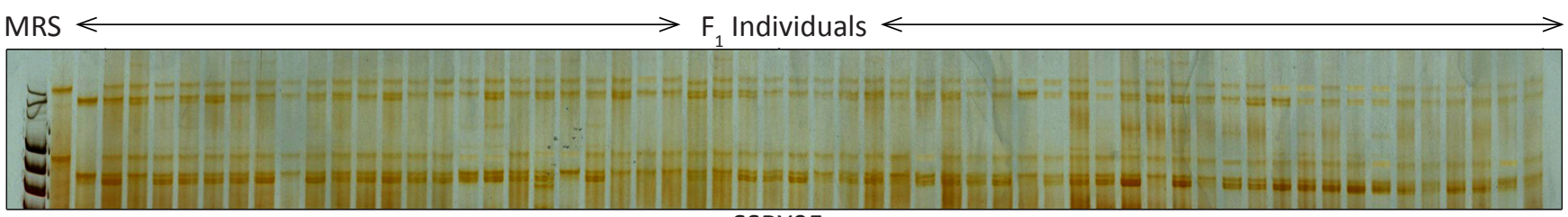

Figure 4: Segregation pattern of SSRY95 in PAGE 


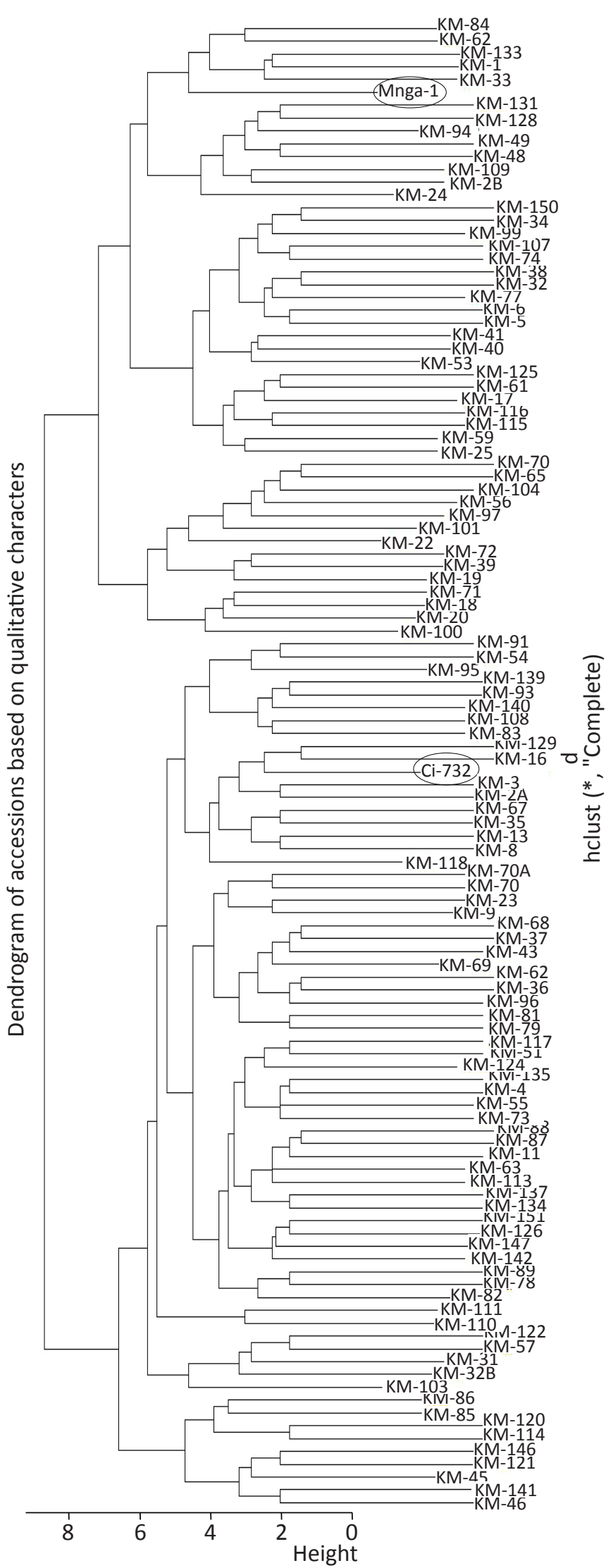

Figure 5: Dendrogram of $F_{1}$ mapping population based on qualitative characters and $65 \mathrm{~F}_{1}$ genotypes, of which KM-2A, KM-3, KM-87, KM-16 and $\mathrm{KM}-129$ were closer to $\mathrm{Cl}-732$. From cluster analysis, it was also found that more than half of the $F_{1}$ progenies (65) acquired morphological characters from female parent indicating the influence of female parent (Figure 5).

\section{Conclusion}

The present study identify CAPS markers and that CAPS markers could be used to map $F_{1}$ mapping population developed from MNga- 1 and $\mathrm{Cl}-732$ and thereby able to locate the regions associated with resistance genes in future. In this study true hybrid evaluation of $F_{1}$ mapping population was carried out to check the hybrid purity which is an essential criteria in inter-hybrid evaluation. Also the molecular characterization of cassava helped to understand the parental contribution in each characters of $F_{1}$ mapping population.

\section{References}

Altschul, S.F., Gish, W., Mille, R.W., Myers, E.W., Lipman, D.J. 1990. Basic local alignment search tool. Journal of Molecular Biology 215(3), 403-410.

Altschul, S.F., Madden, T.L., Schaffer, A.A., Zhang, J., Zhang, Z., Miller, W., Lipman, D.J., 1997. Gapped BLAST and PSI-BLAST: a new generation of protein database search programs. Nucleic Acids Research 25, 3389-3402

Asare, P.A., Galyuon, I.K.A., Sarfo, J.K., Tetteh, J.P., 2011. Morphological and molecular based diversity studies of some cassava (Manihot esculenta Crantz.) germplasm in Ghana. African Journal of Biotechnology 10(63), 13900-13908. doi:http://dx.doi.org/10.5897/AJB11.929

Asif, M., Ur-Rahman, M., Yusuf, Z., 2006. Genotyping analysis of six maize (Zea mays L.) hybrids using DNA fingerprinting technology. Pakistan Journal of Botany 38(5), 1425-1430.

Azhar, M.T., Amin, I., Bashir, A., Mansoor, S., 2011. Characterization of resistance gene analogs from Gossypium arboretum and their evolutionary relationships with homologs from tetraploid cottons. Euphytica 178(3), 351-362. doi:10.1007/s10681-0100310-0

Benesi, I.R.M., Labuschagne, M.T., Herselman, L., Mahungu, N., 2010. Ethnobotany, morphology and genotyping of cassava germplasm from Malawi. Journal of Biological Sciences 10, 616-623. doi: 10.3923/jbs.2010.616.623.

Bent, A.F., 1996. Plant disease resistance genes: Function meets structure. The Plant Cell 8(10), 1757-1771. doi:10.1105/tpc.8.10.1757

Bombarely, A., Menda, N., Tecle, I.Y., Buels, R.M., Strickler, S., Fischer-York, T., Pujar, A., Leto, J., Gossalin, J., Mueller, L.A. 2011. The Sol Genomics Network (solgenomics.net): growing tomatoes using Perl. Nucleic Acids Research 39(1), D1149-D1155. doi: https://doi.org/10.1093/nar/ gkq866.

Bora, A., Choudhury, P.R., Pande, V., Mandal, A.B., 2016. 
Assessment of genetic purity in rice (Oryza sativa L.) hybrids using microsatellite markers. 3 Biotech 6(1), 50. doi:10.1007/s13205-015-0337-y.

Burns. A., Gleadow, R., Cliff, J., Zacarias, A., Cavagnaro, T. 2010. Cassava: The Drought, War and Famine Crop in a Changing World. Sustainability 2, 3572-3607. doi: 10.3390/su2113572

Chen, G., Pan, D., Zhou, Y., Lin, S., Ke, X., 2007. Diversity and evolutionary relationship of nucleotide binding site encoding disease resistance gene analogues in sweet potato (Ipomoea batatas Lam.). Journal of Bioscience $32,713-721$.

Dangl, J.L., Jones, J.D.G., 2001. Plant pathogens and integrated defence responses to infection. Nature 411(6839), 826-833. doi: 10.1038/35081161

Doyle, J.J., Doyle, J.L., 1990. Isolation of plant DNA from fresh tissue. Focus 12, 13-15.

Duputie A., Massol, F., David, P., Haxaire, C., McKey, D., 2009. Traditional Amerindian cultivators combine directional and ideotypic selection for sustainable management of cassava genetic diversity. Journal of Evolutionary Biology 22(6), 1317-1325. doi: 10.1111/j.14209101.2009.01749.x.

FAOSTAT, 2014. Food and Agricultural Commodities Production. Available online: http://faostat.fao.org.

FAOSTAT, 2017. Food and Agricultural Commodities Production. Available online: http://faostat.fao.org.

Fukuda, W.M.G., Guevara, C.L., Kawuki, R., Ferguson, M.E., 2010. Selected morphological and agronomic descriptors for the characterization of cassava. International Institute of Tropical Agriculture (IITA), Ibadan, Nigeria 19.

Gomez, S.M., Denwar, N.N., Ramasubramanian, T., Simpson, C.E., Burow, G., Burke, J.J., Puppala, N., 2008. Identification of peanut hybrids using microsatellite markers and horizontal polyacrylamide gel electrophoresis. Peanut Science 35(2), 123-129. doi: http://dx.doi.org/10.3146/ PS07-109.1.

Goodstein, D.M., Shu, S., Howson, R., Neupane, R., Hayes, R.D., Fazo, J., Mitros, T., Dirks, W., Hellsten, U., Putnam, N., Rokhsar, D.S., 2012. Phytozome: A comparative platform for green plant genomics. Nucleic Acid Research 40, D1178-D1186. Doi: 10.1093/nar.gkr944.

Hahn, S.K., Terry, E.R., Leuschner, K., 1980. Breeding Cassava for resistance to cassava mosaic disease. Euphytica 29(3), 673-683. doi:10.1007/BF00023215

Hammond-Kosack, K.E., Jones, J.D.G., 1997. Plant disease resistance genes. Annual Review Plant Physiology and Plant Molecular Biology 48, 575-607. Doi: 10.1146/ annurev.arplant.48.1.575

Jennifer, L.M.S., Tessa, M.B.S., Savithramma, P.D.K., 2005. Mechanism of plant resistance to virus. Nature Reviews 3, 789-798.

Jones, J.D.G., Dangl, J.L., 2006. The plant immune system. Nature 444(7117), 323-329. doi: 10.1038/nature05286
Legg, J.P., Fauquet, C.M., 2004. Cassava mosaic geminiviruses in Africa. Plant Molecular Biology 56(4), 585-599. doi:10.1007/s11103-004-1651-7.

Lozano, R., Hamblin, M.T., Prochnik, S., Jannink, J.L., 2015. Identification and distribution of the NBS-LRR gene family in the Cassava genome. BMC Genomics 16, 360. doi: 10.1186/s12864-015-1554-9.

Marone, D., Russo, M.A., Laido, G., De Leonardis, A.M., Mastrangelo, A.M., 2013. Plant Nucleotide binding siteLeucine-Rich Repeat (NBS-LRR) genes: active guardians in host defense responses. International Journal of Molecular Science 14(4), 7302-26. Doi: 10.3390/ ijms14047302.

Mbanjo, E.G.N., Tchoumbougnang, F., Mouelle, A.S., Oben, J.E., Nyine, M., Dochez, C., Ferguson, M.E., Lorenzen, J. 2012. Development of expressed sequence tagssimple sequence repeats (EST-SSRs) for Musa and their applicability in authentication of a Musa breeding population. African Journal of Biotechology 11(71), 13546-13559. doi: 10.5897/AJB12.972

Mohan, C., Shanmugasundaram, P., Senthil, N., 2013. Identification of true hybrid progenies in cassava using simple sequence repeat (SSR) markers. Bangladesh Journal of Botany 42(1), 155-159. Doi: http://dx.doi. org/10.3329/bjb.v42i1.15906

Naresh, V., Yamini, K.N., Rajendrakumar, P., Dinesh Kumar, V., 2009. EST-SSR marker-based assay for the genetic purity assessment of safflower hybrids. Euphytica 170(3), 347353. doi:10.1007/s10681-009-9995-3.

Otti, G., Fakoya, A., Andrew, I., Gedil, M., 2011. Development of genomic tools for verification of hybrids and selfed progenies in cassava (Manihot esculenta). African Journal of Biotechnology 10(76), 17400-17408. Doi: 10.5897/AJB11.1946.

Raghu, D., Senthil, N., Saraswathi, T., Raveendran, M., Gnanam, R., Venkatachalam, R., Shanmugasundaram, P., Mohan, C., 2007. Morphological and simple sequence repeats (SSR) based finger printing of South Indian cassava germplasm. International Journal of Integrative Biology 1, 141-148.

Rimoldi, F., Vidigal Filho, P.S., Kvitschal, M.V., GoncalvesVidigal, M.C., Prioli, A.J., Prioli, S.M.A.P., Costa, T.R., 2010. Genetic divergence in sweet cassava cultivars using morphological agronomic traits and RAPD Molecular markers. Brazilian Archives of Biology and Technology 53, 1477-1486. Doi: 10.1590/S151689132010000600025.

Salgado, K.C.P.C., Vieira, M.D.G.G.C., Pinho, E.V.R.V., Guimaraes, C.T., Pinho, R.G.V., Sousa, R.G.V., 2006. Genetic purity certificate in seeds of hybrid maize using molecular markers. Brazilian Journal of Seeds 28(1), 169-175

Sambatti, J.B.M., Martins, P.S., Ando, A., 2001. Folk taxonomy and evolutionary dynamics of cassava: a case study 
in Ubatuba, Brazil. Economic Botany 55, 93-105. Doi: 10.1007/BF02864549

Selvakumar, P., Ravikesavan, R., Gopikrishnan, A., Thiyagu, K., Preetha, S., Manikanda, B.N., 2010. Genetic purity analysis of cotton (Gossypium spp.) hybrids using SSR markers. Seed Science and Technology 38, 358-366.

Semagn, K., Beyene, Y., Makumbi, D., Mugo, S., Prasanna, B.M., Magorokosho, C., Atlin, G., 2012. Quality control genotyping for assessment of genetic identity and purity in diverse tropical maize inbred lines. Theoretical and Applied Genetics 125(7), 1487-1501. Doi: 10.1007/ s00122-012-1928-1

Subashini, V., Shanmugapriya, A., Yasodha, R., 2014. Hybrid purity assessment in Eucalyptus $F_{1}$ hybrids using microsatellite markers. 3Biotechnology 4(4), 367-373. doi: 10.1007/s13205-013-0161-1

Sundaram, R.M., Naveenkumar, B., Biradar, S.K., Balachandran, S.M., Mishra, B., Ilyasahmed, M., Viraktamath, B.C., Ramesha, M.S., Sarma, N.P., 2008. Identification of informative SSR markers capable of distinguishing hybrid rice parental lines and their utilization in seed purity assessment. Euphytica 163, 215-224. doi: 10.1007/ s10681-007-9630-0
Tamilkumar, P., Jerlin, R., Senthil, N., Ganeshan, K.N., Jeevan, R.J., Raveendran, M., 2009. Fingerprinting of rice hybrids and their parental lines using microsatellite markers and their utilization in genetic purity assessment of hybrid rice. Research Journal of Seed Science 3, 40-47. Doi: 10.3923/rjss.2009.40.47

Tarr, D.E., Alexander, H.M., 2009. TIR-NBS-LRR genes are rare in monocots: evidence from diverse monocot orders. BMC Research Notes 2, 197. doi: 10.1186/1756-05002-197

Vasquez, A., Lopez, C., 2012. Identification of polymorphisms in candidate resistance genes in cassava (Manihot esculenta Crantz). Acta Agronomica 61(2), 133-142.

Wu, M., Jia, X., Tian, L., Lv, B., 2006. Rapid and reliable purity identification of F1 hybrids of Maize (Zea may L.) using SSR markers. Molecular Plant Breeding 4, 381-384.

Yashitola, J., Thirumurugan, T., Sundaram, R.M., Naseerullah, M.K., Ramesha, M.S., Sarma, N.P., Sonti, R.V., 2002. Assessment of purity of rice hybrids using microsatellite and STS markers. Crop Science 42, 1369-1373. 